\title{
Rate Coding and the Control of Muscle Force
}

\author{
Roger M. Enoka ${ }^{1}$ and Jacques Duchateau ${ }^{2}$ \\ ${ }^{1}$ Department of Integrative Physiology, University of Colorado, Boulder, Colorado 80309-0354 \\ ${ }^{2}$ Laboratory of Applied Biology and Neurophysiology, Neuroscience Institute, Université Libre de Bruxelles, \\ 1070 Brussels, Belgium \\ Correspondence: enoka@colorado.edu
}

The force exerted by a muscle during a voluntary contraction depends on the number of motor units recruited for the action and the rates at which they discharge action potentials (rate coding). Over most of the operating range of a muscle, the nervous system controls muscle force by varying both motor unit recruitment and rate coding. Except at relatively low forces, however, the control of muscle force depends primarily on rate coding, especially during fast contractions. This review provides five examples of how the modulation of rate coding influences the force exerted by muscle during voluntary actions. The five examples comprise fast contractions, lengthening and shortening contractions, steady isometric contractions, fatiguing contractions, and contractions performed after a change in the daily level of physical activity.

$\mathrm{T}_{\mathrm{t}}^{\mathrm{h}}$ he force exerted by a muscle during a voluntary contraction depends on the number of motor units that are activated and the rates at which these motor units discharge action potentials. These two properties are known as recruitment and rate coding, respectively. Over most of the operating range of a muscle, the force it generates is controlled by concurrent changes in recruitment and rate coding. However, the relative contributions of recruitment and rate coding vary across the operating range. Early experimental evidence suggested that recruitment is the more significant factor at low forces, whereas rate coding is more responsible for changes in muscle force at intermediate and high forces (Milner-Brown et al. 1973b). In this review, we discuss the underappreciated contribution of rate coding to the force produced by muscle during voluntary contractions.
At an elementary level, the relative significance of rate coding can be shown with a computational model of motor unit recruitment and rate coding (Fuglevand et al. 1993). When the forces exerted by each motor unit $(n=120)$ discharging action potentials at a minimal rate $(\sim 8$ pulses per second $[\mathrm{pps}])$ are summed, the result is a net force that is $25 \%$ of the maximal force achieved when all motor units are activated at the assigned peak discharge rates (25$35 \mathrm{pps})$. The $75 \%$ discrepancy between the sum of the motor unit forces produced by minimal discharge rates and the peak force that can be achieved underscores the significant role of rate coding in the control of muscle force. As discussed in the subsequent sections, experimental observations indicate that rate coding has a significant influence on the rate of increase in force during rapid contractions, the control

Editors: Juleen R. Zierath, Michael J. Joyner, and John A. Hawley

Additional Perspectives on The Biology of Exercise available at www.perspectivesinmedicine.org

Copyright (C) 2017 Cold Spring Harbor Laboratory Press; all rights reserved; doi: 10.1101/cshperspect.a029702

Cite this article as Cold Spring Harb Perspect Med 2017;7:a029702 
R.M. Enoka and J. Duchateau

of force during shortening and lengthening contractions, the ability to maintain a constant force during a steady submaximal contraction, the adjustments showed during fatiguing contractions, and the adaptations elicited by changes in physical activity.

\section{RATE CODING AND CONTRACTION SPEED}

The influence of rate coding on motor unit force is characterized experimentally by deriving the force-frequency relation (Macefield et al. 1996). In such an experiment, the axon of a single motor unit is activated with electrical stimuli over a range of frequencies (5-100 pps) and the evoked force is measured. The result is a sigmoidal relation that indicates peak motor unit forces require activation rates of at least 50 pps. In most voluntary contractions involving a gradual increase in force, however, peak discharge rates are usually $<50$ pps (Heckman and Enoka 2012).

Gradual increases in the force exerted by a muscle during an isometric contraction require a progressive increase in motor unit activity, both the recruitment of additional motor units and an increase in discharge rate. The relative contribution of motor unit recruitment to the increase in muscle force is greater during the initial part of the gradual muscle contraction. Recordings of motor unit activity with fine-wire electrodes in which action potentials can be observed directly often show that the peak discharge rate achieved during such tasks is greater for later recruited motor units (Gydikov and Kosarov, 1974; Kanosue et al. 1979; Moritz et al. 2005; Bailey et al. 2007; Barry et al. 2007; Oya et al. 2009). Earlier recruited motor units reach a peak value that tends to remain constant, despite a continual increase in muscle force. This effect is referred to as saturation of discharge rate and is likely attributable to intrinsic mechanisms that limit the capacity of a motor neuron to increase discharge rate despite continual increases in net excitatory synaptic input (Fuglevand et al. 2015).

However, not all studies in which motor unit action potentials have been recorded with fine-wire electrodes have observed saturation of discharge rate for low-threshold motor units and greater peak discharge rates for laterrecruited motor units during gradual increases in muscle force (Person and Kudina 1972; Tanji and Kato 1973; Monster and Chan 1977; De Luca et al. 1982; Duchateau and Hainaut 1990). These different findings are not consistently related to methodological issues, such as the muscle studied or the approach used to quantify recruitment threshold. Also, estimates of motor unit activity derived from multichannel recordings of surface electromyography (EMG) signals in which the action potentials of single motor units cannot be observed directly, invariably report that the earliest recruited motor unit achieve the greatest discharge rates during gradual increases in force (De Luca and Hostage 2010; De Luca and Contessa 2012).

In contrast to the relatively modest changes in discharge rate observed during gradual increases in muscle force, rapid increases in force during ballistic isometric contractions involve instantaneous discharge rates of 60120 pps (Desmedt and Godaux 1979; Van Cutsem and Duchateau 2005). Although the discharge rate increases progressively during gradual increases in muscle force, ballistic contractions are characterized by a high initial discharge rate at the onset of activation and a subsequent decline during successive discharges (Fig. 1A) (Desmedt and Godaux 1977; Bawa and Calancie 1983; Van Cutsem et al. 1998; Klass et al. 2008a). Because of the electromechanical delay between the discharge time of the action potential and onset of force exerted by the motor unit, recruitment thresholds occur at lower forces during rapid contractions presumably caused by the more synchronized arrival of excitatory postsynaptic potentials onto the motor neurons. For example, the upper limit of motor unit recruitment in tibialis anterior declines from $\sim 90 \%$ of maximal force during slow contractions to $\sim 40 \%$ of maximum during rapid contractions (Desmedt and Godaux 1977; Van Cutsem et al. 1997). Consequently, rate coding assumes a more prominent role in the modulation of muscle force during fast contractions. Furthermore, the capacity of motor 
A
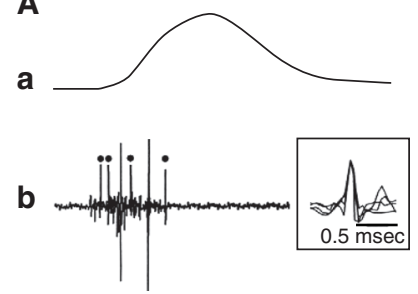

C

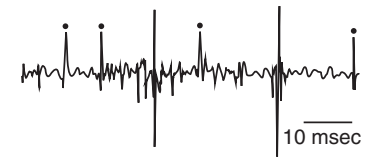

B

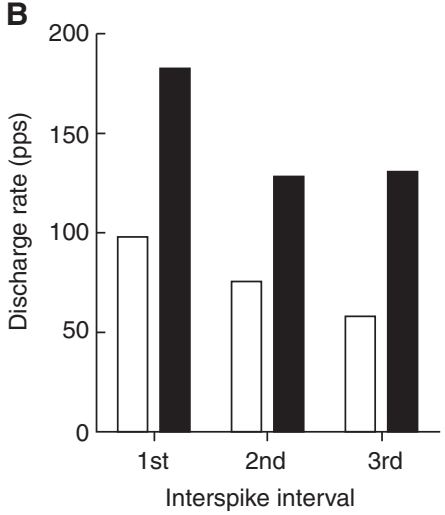

C

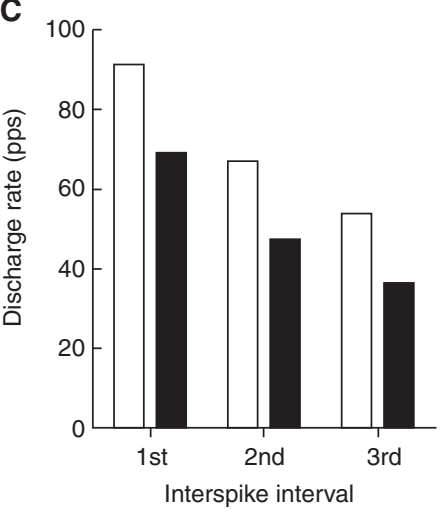

Figure 1. Discharge rates of motor units during ballistic contractions. $(A)$ Action potentials discharged by a single motor unit in tibialis anterior during a ballistic contraction with the ankle dorsiflexor muscles by an untrained subject. The peak force achieved during the submaximal contraction was $\sim 40 \%$ of maximal voluntary contraction (MVC). Traces correspond to the ankle dorsiflexor force ( $a$ ) and intramuscular electromyogram (EMG) plotted at slow $(b)$ and fast $(c)$ speeds. The typical discharge times for tibialis anterior motor units in an untrained person comprised a brief interval between the first two action potentials followed by longer interspike intervals. The dots indicate the discharge of the same motor unit as indicated by the superimposed traces $(b) .(B)$ Average maximal discharge rates for the first three interspike intervals (see trace $c$ in panel $A$ ) during ballistic contractions for tibialis anterior motor units before (white bar) and after 3 months of training (black bar) with rapid contractions (data from Van Cutsem et al. 1998). (C) Average maximal discharge rate for the first three interspike intervals during ballistic contractions for the tibialis anterior motor units in young (white bar) and older adults (black bar) (data from Klass et al. 2008a). pps, Pulses per second.

neurons to discharge action potentials at rates on the plateau of the force-frequency relation during rapid contractions suggests that rate coding is limited during slow changes in force during isometric contractions.

The rate at which motor neurons discharge action potentials is proportional to the synaptic input (descending drive and afferent feedback) they receive. In addition to ionotropic input, rate coding is influenced by the activation of persistent inward currents induced by neuromodulatory input to the motor neuron pool (Heckman and Enoka 2012). Two main neurotransmitters play a role at the motor neuron level: serotonin (5-HT) and norepinephrine. Activity in the descending 5-HT system seems to increase in proportion to motor output, whereas the norepinephrine system varies with the level of arousal (Perrier and Cotel 2015; Aston-Jones and Waterhouse 2016). Neurons that deliver monoaminergic input to motor neurons originate from the raphe nucleus in the brain stem and have monosynaptic connections to the motor neurons. The role of persistent inward currents is to amplify the excitatory synaptic input, thereby increasing the discharge rate of motor neurons. Its action is instantaneous and responsible for the self-sustained discharge of action potentials by motor neurons observed in some conditions and the high initial rate and double discharges at the onset of a ballistic contraction (Heckman et al. 2008).

The maximal discharge rates achieved during ballistic contractions are adaptable. For example, several weeks of training the ankle dorsiflexor muscles to lift a moderate inertial load $(30 \%-40 \%$ of maximal voluntary contraction [MVC] force) with rapid contractions increased both the rate of force development ( $82 \%$ of initial) and the average discharge rate of motor units in tibialis anterior (Van Cutsem et al. 1998). The increase in instantaneous discharge rate is significantly less for the first $(+84 \%)$ and second $(+70 \%)$ interspike intervals than for the third $(+124 \%)$ interspike interval (Fig. 1B). In addition, training with rapid 
R.M. Enoka and J. Duchateau

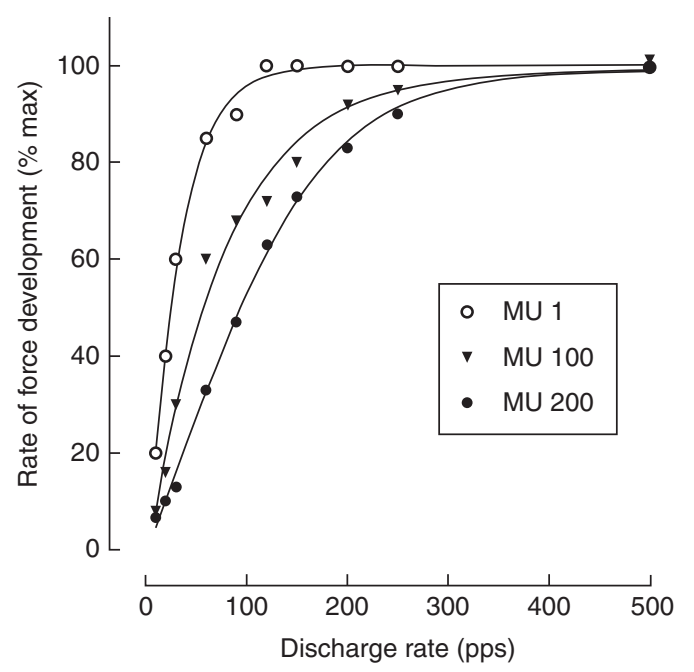

Figure 2. Simulated relations between motor unit discharge rate and maximal rate of force development for motor units (MUs) in the tibialis anterior muscle. The model comprised 200 motor units. The data indicate the relations for the smallest (MU 1), largest (MU 200), and middle (MU 100) motor units. The simulation was based on a model developed by Fuglevand et al. (1993) with the contractile properties of the motor units adjusted to match values measured experimentally for tibialis anterior (Van Cutsem et al. 1998). The force generated by each motor unit was simulated for four successive discharge times generated at constant frequencies ranging from 10 to 500 pps before the first derivative was computed to obtain the maximal rate of force development (data from Duchateau and Baudry 2014). pps, Pulses per second.

contractions increases the number (from $5 \%$ to $33 \%)$ of motor units that show double discharges with discharge rates of greater than 200 pps at the onset of the contraction. Because the time to peak force of the tibialis anterior motor units-as estimated with spike-triggered averaging (Milner-Brown et al. 1973a) —was similar before and after the training intervention, the marked increase in rate of force development during ballistic contractions was attributable to the adaptations in discharge rate.

Another example of the adaptability of maximal discharge rates is the decline observed in older adults. For example, both the rate of force development for ballistic contractions with the ankle dorsiflexors and the maximal discharge rates for motor units in tibialis anterior are reduced in older adults $(71-84 \mathrm{yr})$ relative to young adults (18-22 yr) (Klass et al. 2008a). As observed for gains achieved after training with rapid contractions, the decline in discharge rates showed by older adults was less for the first $(-19 \%)$ and second $(-28 \%)$ interspike intervals than the third $(-34 \%)$ interspike interval (Fig. 1C). In addition, the proportion of tibialis anterior motor units that showed double discharges greater than 200 pps was less for older (4.6\%) than young (8.4\%) adults.

These two examples suggest that the initial component of the increase in force during rapid contractions is constrained by the capacity of motor neurons to discharge action potentials at high rates. This association and the underlying mechanisms were examined with a computational model (Fuglevand et al. 1993). When the motor units in the model were assigned experimentally observed contractile properties (Van Cutsem et al. 1998), an increase in peak discharge rates to the range of $100-$ 200 pps substantially augmented the rate of force development for all motor units in the population (Fig. 2) (Duchateau and Baudry 2014). Further increases in discharge rate only increased the rate of force development for the fastest-contracting motor units, as expected from the difference in speed-related properties of low- and high-threshold motor units (Kernell 1992). 
Taken together, these experimental and modeling studies underscore the critical role of maximal motor unit discharge rates in limiting the rate of force development at the onset of a ballistic contraction (Duchateau and Baudry 2014). Greater rates of force development are an advantage in physical activities in which there is only a brief period of time to develop as much force as possible to increase the forcetime impulse. In contrast, the age-related reduction in the rate of force development attenuates the capacity of older adults to perform fast movements and to react quickly to perturbations that compromise balance.

\section{RATE CODING DURING SHORTENING AND LENGTHENING CONTRACTIONS}

When an action requires a change in muscle length, the net motor unit activity must be controlled to produce the desired trajectory. In addition to the magnitude and speed of the required displacement, the modulation of motor unit discharge rate depends on whether the activated muscle shortens or lengthens during the prescribed action. Because of the greater force capacity of muscle during lengthening contractions (Altenburg et al. 2009), the same absolute muscle force can be generated with less motor unit activity during lengthening contractions than during shortening contractions (Duchateau and Enoka 2016). Although shortening contractions typically involve the recruitment of more motor units than during lengthening contractions, those motor units that are active during both the shortening and lengthening phases of an action show lower discharge rates during the lengthening contraction (Pasquet et al. 2006).

To show that the neural drive to a muscle (number of motor unit action potentials) differs during lengthening and shortening contractions, it is necessary to compare motor unit activity when the biomechanical requirements of a task are similar for the two types of contractions. Pasquet et al. (2006) performed such a study by comparing the activity of motor units in tibialis anterior when the dorsiflexors pushed against a torque motor over a 20-degree range of motion (10 degrees/sec) about the ankle joint. Each action began with an isometric contraction and then the torque motor either allowed the dorsiflexor muscles to shorten or produced a torque that was sufficient to lengthen the activated muscles. A key finding of this study was that the discharge rate of the identified motor units (recruitment thresholds: $0.2 \%-32.8 \%$ MVC force) remained relatively constant during the entire lengthening contraction (12.6 \pm 2.0 pps; mean \pm SEM $)$, whereas it increased progressively from the start $(12.6 \pm 2.0 \mathrm{pps})$ to the end $(14.5 \pm$ $2.5 \mathrm{pps}$ ) of the shortening contraction (Fig. 3) despite similar changes in muscle fascicle length and velocity as determined by ultrasonography. Because the order in which motor units are recruited does not differ during shortening and lengthening contractions (Duchateau and Enoka 2016) and the torque generated by the dorsiflexors was similar during the two types of contractions (Pasquet et al. 2006), the greater discharge rate at the end of the shortening contraction was likely necessary to accommodate the decline in force capacity of muscle fibers at short lengths. Nonetheless, discharge rate was not greater at the start of the lengthening contraction when the tibialis anterior muscle was at a short length.

As reviewed by Duchateau and Enoka (2016), the differential modulation of motor unit discharge rate during shortening and lengthening contractions involves neural pathways at both the spinal and supraspinal levels. One consequence of the lower motor unit discharge rate during lengthening contractions is that it explains, at least in part, the lesser metabolic demand during lengthening relative to shortening contractions (Bigland-Ritchie and Woods 1976).

\section{COMMON INPUT AND FORCE STEADINESS}

When performing a steady isometric contraction, the applied force fluctuates about an average value. The standard deviation of these force fluctuations, which provides a measure of force steadiness (Galganski et al. 1993), increases with the magnitude of the target force caused by the 
R.M. Enoka and J. Duchateau

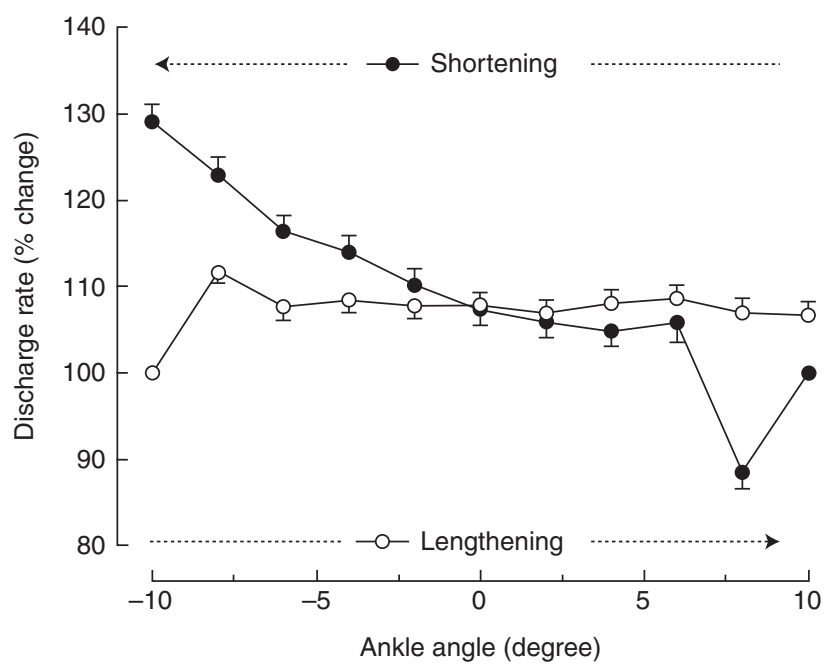

Figure 3. Average ( \pm SEM) discharge rate of motor units $(n=63)$ in tibialis anterior during slow (10 degrees/ $\mathrm{sec}$ ) shortening and lengthening contractions. The shortening contraction (filled circles) began from a long muscle length (10 degrees), whereas the lengthening (open circles) contraction began from a short muscle length ( -10 degrees). Each action began with an isometric contraction before the torque motor that controlled the angular displacement of a footplate either allowed the dorsiflexors to shorten or generated a torque that was sufficient to lengthen the activated muscles. The discharge rate at each joint angle averaged more than $0.2-\mathrm{sec}$ bins for all motor units and was expressed relative to the value recorded during the initial isometric contraction (data from Pasquet et al. 2006).

progressive recruitment of motor units discharging action potentials at submaximal rates (Moritz et al. 2005). The normalized measure of force steadiness (coefficient of variation for force) is often greater for older adults than younger adults, especially during low-force contractions (Enoka et al. 2003), and can explain significant amounts of the variance in measures of motor performance, such as the time to complete a pegboard test of manual dexterity (Almuklass et al. 2016b) and the walking performance of individuals with multiple sclerosis (Almuklass et al. 2016a). For example, $70 \%$ of the variance in the time it takes young adults to complete the grooved pegboard test $(41.5-67.5 \mathrm{sec})$ can be explained by two predictor variables: (1) time to match a submaximal target force during a rapid pinching action with the index finger and thumb; and (2) coefficient of variation for force (steadiness) during a steady contraction with the wrist extensors at 10\% MVC force (Almuklass et al. 2016b). Similarly, $\sim 50 \%$ of variance in walking speed (time to walk $25 \mathrm{ft}$ ) and walking endurance (distance walked in $6 \mathrm{~min}$ ) for individuals who are moderately impaired by multiple sclerosis can be explained by dorsiflexor torque steadiness at $20 \%$ MVC and the coefficient of variation for interspike interval of motor units in tibialis anterior during a steady contraction at $10 \%$ MVC force (Almuklass et al. 2016a).

Differences in force steadiness across tasks and individuals depend more on the discharge characteristics than force capacity of the active motor units (Enoka et al. 2003). Although some evidence has indicated an association between force steadiness and variability in discharge times of individual motor units (Laidlaw et al. 2000; Mortiz et al. 2005), this finding is not consistent (Semmler et al. 2000; Barry et al. 2007; Negro et al. 2009). Rather, differences in force steadiness depend more on the cumulative activity of the recruited motor units (Semmler et al. 2006; Dideriksen et al. 2012). Farina and colleagues, for example, showed that $74 \%$ of the variance in muscle force during steady contrac- 
tions with a hand muscle could be explained by low-frequency modulation $(\leq 10 \mathrm{~Hz})$ of motor unit discharge times, which was attributed to the common synaptic input received by the motor neurons (Negro et al. 2009; Farina and Negro 2015; Farina et al. 2016). Moreover, the proportion of common input increases with target force and during sustained isometric contractions (Castronovo et al. 2015). Consequently, improvements in force steadiness after various training interventions (Keen et al. 1994; Bilodeau et al. 2000; Tracy et al. 2004; Marmon et al. 2011) should be accompanied by a reduction in the variability of common input to the involved motor neurons (see Fig. 7 in Farina and Negro 2015). For example, Farina et al. (2012) showed that an increase in force variability caused by an induced increase in muscle pain was explained by an increase in the variability of the common input signal, as estimated by the low-frequency bandwidth of the cumulative motor unit discharge times.

Decreases in force variability during steady contractions and the accompanying practiceassociated improvement in manual dexterity (Marmon et al. 2011), therefore, were presumably attributable to a reduction in the variability of the common input signal. Similarly, the greater force variability showed by older adults at low forces (Galganski et al. 1993; Christou and Carlton, 2001) is likely caused by greater variability in the common input signal, which can be improved with physical training (Christou et al. 2003). Despite these associations, essentially nothing is known about the source of the common input to the motor unit pools responsible for these effects.

\section{ADJUSTMENTS IN RATE CODING DURING PROLONGED ACTIVITY}

When a motor unit is recruited to participate in a prescribed task, the rate at which it discharges action potentials changes over time. The adjustments in discharge rate are attributable to changes in the intrinsic properties of the motor neuron and the synaptic inputs it receives. In a classic demonstration of the significance of intrinsic properties, Kernell and Monster (1982) recorded the decline in discharge rate when single motor neurons were activated with a constant level of injected current above activation threshold. The typical result, as indicated for one motor neuron in Figure 4A, comprised an initial $(<2 \mathrm{sec})$ rapid and then more gradual decline in discharge rate. The decrease in discharge rate from $2 \mathrm{sec}$ to $26 \mathrm{sec}$ was termed late adaptation and its magnitude was positively correlated $(r=$ 0.93 ) with the initial discharge rate of the motor neuron.

When a task involves sustaining a submaximal target force for a prescribed duration, therefore, additional motor units must be recruited to compensate for the decrease in motor unit discharge rate due to the decline in responsiveness of a motor neuron to an applied current. The magnitude of the depression in motor neuron responsiveness has been estimated by measuring the time it takes the level of muscle activation to recover after a sustained, low-force isometric contraction (Héroux et al. 2016). The approach involved participants sustaining the discharge of an identified motor unit in triceps brachii at $\sim 10$ pps for $\sim 260 \mathrm{sec}$ and then after several different recovery periods $(1-240 \mathrm{sec})$ repeating the task and determining the time course of the return in EMG amplitude to initial values. An increase in EMG amplitude indicated a greater number of muscle fiber action potentials (Enoka and Duchateau 2015) and, hence, more synaptic input to the motor neuron pool to achieve the required discharge rate of the identified motor unit. The increase in EMG amplitude declined exponentially with a time constant of $28 \mathrm{sec}$, but recovery was not complete until $\sim 240 \mathrm{sec}$. The decline in motor neuron responsiveness during prolonged activation, however, can be compensated for by increasing the synaptic inputs to the motor neurons as indicated by the finding that humans are able to sustain the discharge rate $(10.6 \pm 1.8$ pps; mean \pm SD) of motor units in first dorsal interosseus for $21.4 \pm 17.8 \mathrm{~min}$ during a low-force $(5.5 \% \pm 2.8 \% \mathrm{MVC})$ isometric contraction (Pascoe et al. 2014).

In addition to the decline in motor neuron responsiveness during prolonged activation, motor unit recordings indicate that the reduc- 
R.M. Enoka and J. Duchateau
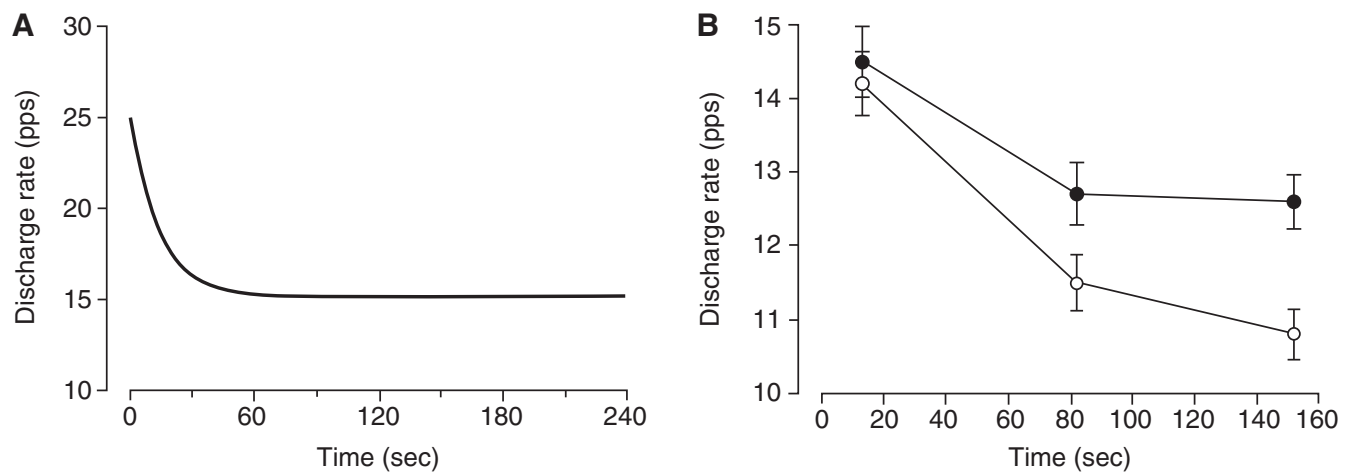

Figure 4. Declines in motor unit discharge rate during prolonged activation. $(A)$ Decrease in discharge rate for a cat motor neuron that was activated by sustained intracellular current injection. The motor neuron innervated the medial gastrocnemius muscle. The injected current was $\sim 5 \mathrm{nA}$ greater than the amplitude required to elicit the repetitive discharge of action potentials. The gradual decline in discharge rate that began a few seconds after the onset of stimulation and lasted for $\sim 30 \mathrm{sec}$ is known as "late adaptation" (Kernell and Monster 1982). (B) Decrease in discharge for motor units in biceps brachii $(n=64)$ during submaximal isometric contractions with the elbow flexor muscles. Average target force was $\sim 25 \%$ maximal voluntary contraction (MVC). In one condition (filled circles), the participant was required to match the target force displayed on a monitor for a prescribed duration. In the other condition (open circles), the participant generated the same net muscle torque about the elbow joint and was required to maintain a constant elbow joint angle for the same duration by matching the measured joint angle to the target displayed on the monitor (data from Mottram et al. 2005 and Gould et al. 2016). pps, Pulses per second.

tion in discharge rate can be modulated by the synaptic inputs received by the motor neurons. When performing a series of intermittent, isometric contractions to a target of $50 \%$ MVC force, Carpentier et al. (2001) found that the discharge rate of motor units recruited from the onset of the task declined progressively, whereas the discharge rate of motor units recruited during the task initially increased before subsequently decreasing. Despite a progressive increase in the neural drive to the muscle during the fatiguing contraction, as indicated by the recruitment of additional motor units and an increase in EMG amplitude, the decline in discharge rate was attributed to motor neuron adaptation and to changes in afferent feedback from the active muscle (for an explanation of mechanisms, see Taylor et al. 2016).

The critical role of afferent feedback has been underscored with a protocol that compares the influence of load type on fatigability during sustained isometric contractions. A number of studies have shown that task failure occurs more quickly when submaximal inertial loads
( $\leq 35 \%$ of maximum) are supported by a limb compared with pulling at an equivalent force against a rigid restraint (Hunter et al. 2002; Maluf et al. 2005; Klass et al. 2008b). For example, time to failure for the elbow flexors when pulling against a rigid restraint to match a target force of $15 \%$ MVC was $1402 \pm 728 \mathrm{sec}$ (mean \pm SD) compared with $702 \pm 582 \mathrm{sec}$ when generating the same net muscle torque to support an inertial load (Hunter et al. 2002). The various durations of the two tasks, however, differs across loads, muscles, and limb posture (Maluf et al. 2005; Rudroff et al. 2010, 2011). The briefer time to failure for the inertial-load condition is associated with a more rapid decline in discharge rate (Fig. 4B) and a greater recruitment of additional motor units (Mottram et al. 2005). Moreover, the modulation of spinal reflex pathways is more pronounced when supporting the inertial load (Klass et al. 2008b; Rudroff et al. 2010). The different rates of adjustment in discharge rate for the two load conditions, therefore, appear to be attributable to differences in afferent feedback onto the motor neurons. 
At a functional level, these results indicate that sustaining a submaximal force is easiest when the limb acts against a rigid restraint and the amount of muscle activity necessary to maintain the posture is minimal. These results indicate the conditions that will minimize metabolic costs of physical activity and, hence, the optimal design of workstations, and conversely how to manipulate exercise intensity during a rehabilitation program.

\section{ADAPTATIONS IN RATE CODING ELICITED BY CHANGES IN PHYSICAL ACTIVITY}

Interventions that manipulate the amount of physical activity for several weeks can produce significant adaptations in rate coding. Not surprisingly, the change in rate coding depends on the details of the intervention. For example, Vila-Chã et al. (2010) compared the adaptations in muscle function and motor unit activation in individuals who performed 6 weeks of either strength training (load of $60 \%-70 \%$ of onerepetition maximum) or endurance training (20-50 min of cycling at $50 \%-75 \%$ of heart rate reserve). As expected, the strength-training group showed an increase in the MVC force for the knee extensors, whereas the endurancetraining group experienced a reduction in fatigability when sustaining an isometric contraction with the knee extensors at 30\% MVC force. Moreover, the change in discharge rate of motor units in the vasti muscles during an isometric contraction at 30\% MVC force differed for the two groups; it decreased for the endurancetraining group $(11.3 \pm 1.5$ to $10.1 \pm 1.1 \mathrm{pps}$; mean \pm SEM) and increased for the strengthtraining group $(11.4 \pm 1.2$ to $12.7 \pm 1.3 \mathrm{pps})$. These findings indicate that the relative contributions of rate coding and recruitment to the same normalized force (30\% MVC) changed differently after the two training programs.

Similarly, interventions that reduce the amount of physical activity often decrease rate coding. For example, the decline in MVC force after a period of reduced activity is attributable to both the loss of muscle mass and a decrease in muscle activation (Duchateau and Hainaut 1987). At the motor unit level, 6-8 wk of im- mobilization of hand muscles (first dorsal interosseus and adductor pollicis) induces a relatively uniform decrease in force across the entire motor unit pool without any change in recruitment order (Duchateau and Hainaut 1990). In addition, peak discharge rates for motor units in first dorsal interosseus declined markedly after the period of immobilization from $31 \pm 8.9$ to $19 \pm 4.9$ pps (mean \pm SD) during gradual increases in muscle force. Given that the initial discharge rate at recruitment did not change after immobilization, the range of rate coding was depressed by the period of reduced activity. The decline in rate coding was more pronounced for motor units in the lower half of the recruitment range.

The functional significance of the decline in motor unit force and rate coding after several weeks of immobilization was evaluated by assigning the observed properties to motor units in a computational model (Fig. 5A) (Fuglevand et al. 1993). The reduction in the simulated MVC force (41\%) was similar to that observed experimentally (44\%) (Duchateau and Hainaut 1990; Duchateau and Enoka 2002). To estimate the contribution of the decline in rate coding to the decrease in MVC force, motor units in the model were assigned spike-triggered average forces measured in the control condition and peak discharge rates recorded after the period of immobilization. With these parameters, the simulated MVC force was reduced by $18 \%$ (Fig. 5B). Hence, the $41 \%$ reduction in MVC force after the period of reduced activity was attributable to decreases in both rate coding (18\%) and motor unit force (23\%).

Taken together, the measurements of motor unit activity after a change in the daily level of physical activity indicate that adaptations in rate coding contribute significantly to the relative increases and decreases in performance.

\section{CONCLUDING REMARKS}

With the exception of fast contractions, most voluntary actions involve motor units discharging action potentials in the range of 10-30 pps. Because of the changes in synaptic inputs and the intrinsic properties of motor neurons, dis- 
R.M. Enoka and J. Duchateau
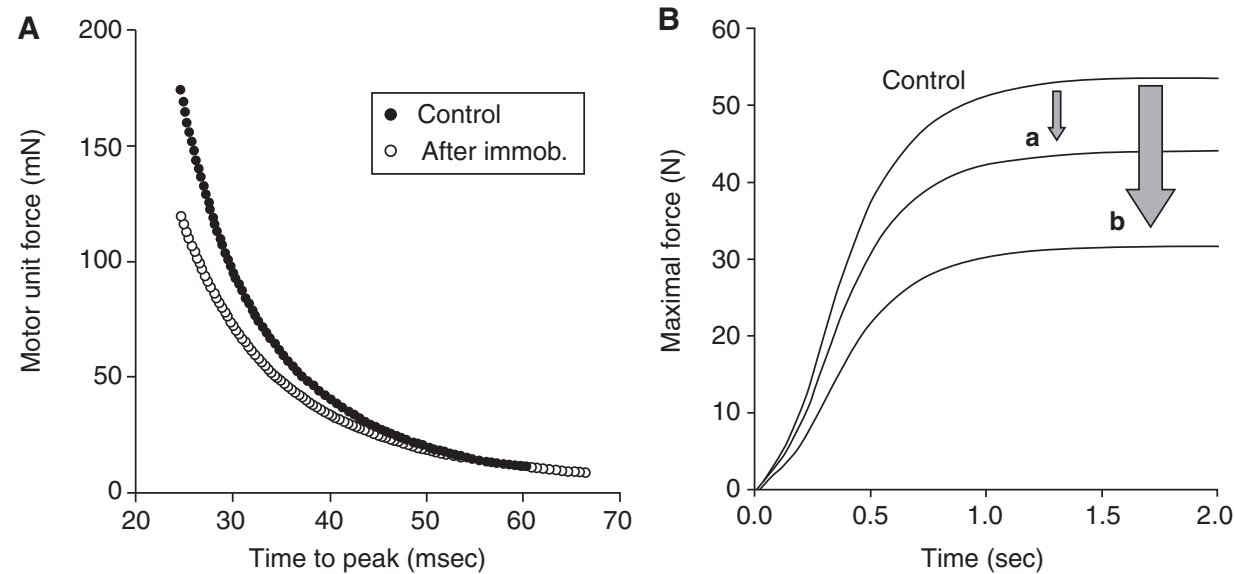

Figure 5. Adaptations in the contractile properties of motor units after several weeks of limb immobilization. $(A)$ Relation between peak force and time to peak force for motor units in the first dorsal interosseus muscle as estimated with spike-triggered averaging before (control) and after $6-8$ wk of immobilization (immob.). Each relation comprises 100 units based on experimental measurements (Duchateau and Hainaut 1990). (B) Comparison of the simulated maximal voluntary contraction (MVC) force before (control) and after ( $a$ and $b)$ the immobilization intervention. The simulation was based on the model developed by Fuglevand et al. (1993) and comprised motor units with properties shown in $A$. The simulated forces indicate $(a)$ the reduction in MVC force caused by the decrease of maximal discharge rate alone, and $(b)$ the decline in MVC force caused by the decrease in motor unit force and maximal discharge rate (data from Duchateau and Enoka 2002).

charge rate is often modulated by $5-10 \mathrm{pps}$ across such tasks as submaximal steady contractions, lengthening and shortening contractions, and fatiguing contractions. Although the magnitude of the variation in discharge rate may seem trivial, it is important to emphasize that the rates at which motor units discharge during these tasks lie on the steep portion of the force-frequency relation, which results in small changes in discharge rate producing relatively large changes in motor unit force (Macefield et al. 1996; Fuglevand et al. 2015). In contrast, more prolonged increases or decreases in physical activity typically elicit greater adaptations in discharge rate that have a more pronounced influence on maximal force or rate of force development. These observations indicate that the modulation of discharge rate (rate coding) by the nervous system contributes significantly to a range of voluntary actions.

\section{REFERENCES}

Almuklass A, Davis L, Vieira T, Botter A, Derqaoui K, Hamilton L, Hebert JR, Vollmer TL, Alvarez E, Enoka RM. 2016a. Neuromuscular determinants for walking performance in individuals with multiple sclerosis. Med Sci Sports Exerc 48: 712.

Almuklass AM, Price RC, Gould JR, Enoka RM. 2016b. Force steadiness as a predictor of time to complete a pegboard test of dexterity in young men and women. J Appl Physiol 120: 1410-1417.

Altenburg TM, de Ruiter CJ, Verdijk PW, van Mechelen W, de Haan A. 2009. Vastus lateralis surface and single motor unit electromyography during shortening, lengthening and isometric contractions corrected for mode-dependent differences in force-generating capacity. Acta Physiol (Oxford) 196: 315-328.

Aston-Jones G, Waterhouse B. 2016. Locus coeruleus: From global projection system to adaptive regulation of behavior. Brain Res 1645: 75-78.

Bailey EF, Rice AD, Fuglevand AJ. 2007. Firing patterns of human genioglossus motor units during voluntary tongue movement. J Neurophysiol 97: 933-936.

Barry BK, Pascoe MA, Jesunathadas M, Enoka RM. 2007. Rate coding is compressed but variability is unaltered for motor units in a hand muscle of old adults. J Neurophysiol 97: 3206-3218.

Bawa P, Calancie B. 1983. Repetitive doublets in human flexor carpi radialis muscle. J Physiol 339: 123-132.

Bigland-Ritchie B, Woods JJ. 1976. Integrated electromyogram and oxygen uptake during position and negative work. J Physiol 260: 267-277.

Bilodeau M, Keen DA, Sweeney PJ, Shields RW, Enoka RM. 2000. Strength training can improve steadiness in persons with essential tremor. Muscle Nerve 23: 771-778. 
Carpentier A, Duchateau J, Hainaut K. 2001. Motor unit behavior and contractile changes during fatigue in the human first dorsal interosseus. J Physiol 534: 903-912.

Castronovo AM, Negro F, Conforto S, Farina D. 2015. The proportion of common synaptic input to motor neurons increases with an increase in net excitatory input. J Appl Physiol 119: 1337-1346.

Christou EA, Carlton LG. 2001. Old adults exhibit greater motor output variability than young adults only during rapid discrete isometric contractions. J Gerontol Biol Sci 56: B524-B532.

Christou EA, Yang Y, Rosengren KS. 2003. Taiji training improves knee extensor strength and force control in older adults. J Gerontol 58: 763-766.

De Luca CJ, Contessa P. 2012. Hierarchical control of motor units in voluntary contractions. J Neurophysiol 107: 178-195.

De Luca CJ, Hostage EC. 2010. Relationship between firing rate and recruitment threshold of motoneurons in voluntary isometric contractions. J Neurophysiol 104: 10341046.

De Luca CJ, LeFever RS, McCue MP, Xenakis AP. 1982. Behaviour of human motor units in different muscles during linearly varying contractions. J Physiol 329: 113-128.

Desmedt JE, Godaux E. 1977. Ballistic contractions in man: Characteristic recruitment pattern of single motor unit of the tibialis anterior muscle. J Physiol 264: 673-693.

Desmedt JE, Godaux E. 1979. Voluntary motor commands in human ballistic movements. Ann Neurol 5: 415-421.

Dideriksen JL, Negro F, Enoka RM, Farina D. 2012. Motor unit recruitment strategies and muscle properties determine the influence of synaptic noise on force steadiness. J Neurophysiol 107: 3357-3369.

Duchateau J, Baudry S. 2014. Maximal discharge rate of motor units determines the maximal rate of force development during ballistic contractions in human. Front Human Neurosci 8: 234

Duchateau J, Enoka RM. 2002. Neural adaptations with chronic activity patterns in able-bodied humans. Am J Phys Med Rehabil 81: S17-S27.

Duchateau J, Enoka RM. 2016. Neural control of lengthening contractions. J Exp Biol 219: 197-204.

Duchateau J, Hainaut K. 1987. Electrical and mechanical changes in immobilized human muscle. J Appl Physio 62: $2168-2173$.

Duchateau J, Hainaut K. 1990. Effects of immobilization on contractile properties, recruitment and firing rates of human motor units. J Physiol 422: 55-65.

Enoka RM, Duchateau J. 2015. Inappropriate interpretation of surface EMG signals and muscle fiber characteristics impedes understanding of the control of neuromuscular function. J Appl Physiol 119: 1516-1518.

Enoka RM, Christou EA, Hunter SK, Kornatz KW, Semmler JG, Taylor AM, Tracy BL. 2003. Mechanisms that contribute to differences in motor performance between young and old adults. J Electromyogr Kinesiol 13: 1-12.

Farina D, Negro F. 2015. Common synaptic input to motor neurons, motor unit synchronization, and force control. Exerc Sport Sci Rev 43: 23-33.

Farina D, Negro F, Gizzi L, Falla D. 2012. Low-frequency oscillations of the neural drive to the muscle are increased
Motor Unit Discharge Rates and Muscle Force

with experimental muscle pain. J Neurophysiol 107: 958965.

Farina D, Negro F, Muceli S, Enoka RM. 2016. Principles of motor unit physiology evolve with advances in technology. Physiology 31: 83-94.

Fuglevand AJ, Winter DA, Patla AE. 1993. Models of recruitment and rate coding organization in motor-unit pool. J Neurophysiol 70: 2470-2488.

Fuglevand AJ, Lester RA, Johns RK. 2015. Distinguishing intrinsic from extrinsic factors underlying firing rate saturation in humans. J Neurophysiol 113: 1310-1322.

Galganski ME, Fuglevand AJ, Enoka RM. 1993. Reduced control of motor output in a human hand muscle of elderly subjects during submaximal contractions. J Neurophysiol 69: 2108-2115.

Gould JR, Cleland BT, Mani D, Amiridis IG, Enoka RM. 2016. Motor unit activity in biceps brachii of left-handed humans during sustained contractions with two load types. J Neurophysiol 116: 1358-1365.

Gydikov A, Kosarov D. 1974. Some features of different motor units in human biceps brachii. Pflügers Arch 347: $75-88$.

Heckman CJ, Enoka RM. 2012. Motor unit. Compr Physiol 2: $2629-2682$.

Heckman CJ, Johnson M, Mottram C, Schuster J. 2008. Persistent inward currents in spinal motoneurons and their influence on human motoneuron firing patterns. Neuroscientist 14: 264-275.

Héroux ME, Butler AA, Gandevia SC, Taylor JL, Butler JE. 2016. Time course of human motoneuron recovery after sustained low-level voluntary activity. J Neurophysiol 115: 803-812.

Hunter SK, Ryan DL, Ortega JD, Enoka RM. 2002. Task differences with the same load torque alter the endurance time of submaximal fatiguing contractions in humans. J Neurophysiol 88: 3087-3096.

Kanosue K, Yoshida M, Akazawa K, Fuji K. 1979. The number of active motor units and their firing rates in voluntary contraction of human brachialis muscle. Jpn J Physiol 29: $427-443$.

Keen DA, Yue GH, Enoka RM. 1994. Training-related enhancement in the control of motor output in elderly humans. J Appl Physiol 77: 2648-2658.

Kernell D. 1992. Organized variability in the neuromuscular system: A survey of task-related adaptations. Arch Ital Biol 130: 19-66.

Kernell D, Monster AW. 1982. Time course and properties of late adaptation in spinal motoneurones of the cat. Exp Brain Res 46: 191-196.

Klass M, Baudry S, Duchateau J. 2008a. Age-related decline in rate of torque development is accompanied by lower maximal motor unit discharge frequency during fast contractions. J Appl Physiol 104: 739-746.

Klass M, Lévénez M, Enoka RM, Duchateau J. 2008b. Spinal mechanisms contribute to differences in the time to failure of submaximal fatiguing contractions performed with different loads. J Neurophysiol 99: 1096-1104.

Laidlaw DH, Bilodeau M, Enoka RM. 2000. Steadiness is reduced and motor unit discharge is more variable in old adults. Muscle Nerve 23: 600-612. 
R.M. Enoka and J. Duchateau

Macefield VG, Fuglevand AJ, Bigland-Ritchie B. 1996. Contractile properties of single motor units in human toe extensors assessed by intraneural motor axon stimulation. J Neurophysiol 75: 2509-2519.

Maluf KS, Shinohara M, Stephenson JL, Enoka RM. 2005. Muscle activation and time to task failure differ with load type and contraction intensity for a human hand muscle Exp Brain Res 167: 165-1777.

Marmon AR, Gould JR, Enoka RM. 2011. Practicing a functional task improves steadiness with hand muscles in older adults. Med Sci Sports Exerc 43: 1531-1537.

Milner-Brown HS, Stein RB, Yemm R. 1973a. The contractile properties of human motor units during voluntary isometric contractions. J Physiol 228: 285-306.

Milner-Brown HS, Stein RB, Yemm R. 1973b. Changes in firing rate of human motor units during linearly changing voluntary contractions. J Physiol 230: 371-390.

Monster AW, Chan H. 1977. Isometric force production by motor units of extensor digitorum communis muscle in man. J Neurophysiol 40: 1432-1443.

Moritz CT, Barry BK, Pascoe MA, Enoka RM. 2005. Discharge rate variability influences the variation in force fluctuations across the working range of a hand muscle. J Neurophysiol 93: 2449-2459.

Mottram CJ, Jakobi JM, Semmler JG, Enoka RM. 2005. Motor-unit activity differs with load type during a fatiguing contraction. J Neurophysiol 93: 1381-1392.

Negro F, Holobar A, Farina D. 2009. Fluctuations in isometric muscle force can be described by one linear projection of low-frequency components of motor unit discharge rates. J Physiol 587: 5925-5938.

Oya T, Riek S, Cresswell AG. 2009. Recruitment and rate coding organization for soleus motor units across entire range of voluntary isometric plantar flexions. J Physiol 587: $4737-4748$

Pascoe MA, Holmes MR, Stuart DG, Enoka RM. 2014. Discharge characteristics of motor units during long-duration contractions. Exp Physiol 99: 1387-1398.

Pasquet B, Carpentier A, Duchateau J, Hainaut K. 2006. Specific modulation of motor unit discharge for a similar change in fascicle length during shortening and lengthening contractions in humans. J Physiol 577: 753-765.

Perrier JF, Cotel F. 2015. Serotonergic modulation of spinal motor control. Curr Opin Neurobiol 33: 1-7.

Person RS, Kudina LP. 1972. Discharge frequency and discharge pattern of human motor units during voluntary contraction of muscle. Electroenceph Clin Neurophysiol 32: $471-483$

Rudroff T, Jordan K, Enoka JA, Matthews SD, Baudry S, Enoka RM. 2010. Discharge of biceps brachii motor units is modulated by load compliance and forearm posture. Exp Brain Res 202: 111-120.

Rudroff T, Justice JN, Holmes MR, Matthews SD, Enoka RM. 2011. Muscle activity and time to failure differ with load compliance and target force for elbow flexors. J Appl Physiol 110: 125-136.

Semmler JG, Steege JW, Kornatz KW, Enoka RM. 2000. Motor-unit synchronization is not responsible for larger motor-unit forces in old adults. J Neurophysiol 84: 358 366.

Semmler JG, Kornatz KW, Meyer FG, Enoka RM. 2006. Diminished task-related adjustments of common inputs to hand muscle motor neurons in older adults. Exp Brain Res 172: 507-518.

Tanji J, Kato M. 1973. Firing rate of individual motor units in voluntary contraction of abductor digiti minimi muscle in man. Exp Neurol 40: 771-783.

Taylor JL, Amann M, Duchateau J, Meeussen R, Rice CL. 2016. Neural contributions to muscle fatigue: From the brain to the muscle and back again. Med Sci Sports Exerc 48: 2294-2306.

Tracy BL, Byrnes WC, Enoka RM. 2004. Strength training reduces force fluctuations during anisometric contractions of the quadriceps femoris in old adults. J Appl Physiol 96: 1530-1540.

Van Cutsem M, Duchateau J. 2005. Preceding muscle activity influences motor unit discharge and rate of torque development during ballistic contractions in humans. J Physiol 562: 635-644.

Van Cutsem M, Feireisen P, Duchateau J, Hainaut K. 1997. Mechanical properties and behaviour of motor units in the tibialis anterior during voluntary contractions. Can J Appl Physiol 22: 585-597.

Van Cutsem M, Duchateau J, Hainaut K. 1998. Changes in single motor unit behavior contribute to the increase in contraction speed after dynamic training in humans. J Physiol 513: 295-305.

Vila-Chã C, Falla D, Farina D. 2010. Motor unit behavior during submaximal contractions following six weeks of either endurance or strength training. J Appl Physiol 109: 1455-1466. 


\section{$\&_{\mathrm{CSH}}^{\infty} \&$ Cold Spring Harbor

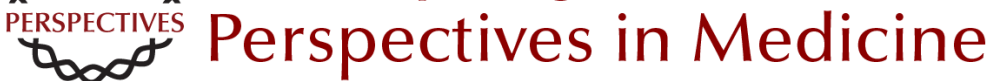

\section{Rate Coding and the Control of Muscle Force}

Roger M. Enoka and Jacques Duchateau

Cold Spring Harb Perspect Med 2017; doi: 10.1101/cshperspect.a029702 originally published online March 27, 2017

\section{Subject Collection The Biology of Exercise}

Exosomes as Mediators of the Systemic

Adaptations to Endurance Exercise Adeel Safdar and Mark A. Tarnopolsky

Molecular Basis of Exercise-Induced Skeletal

Muscle Mitochondrial Biogenesis: Historical

Advances, Current Knowledge, and Future

Challenges

Christopher G.R. Perry and John A. Hawley

Exercise Metabolism: Fuels for the Fire Mark Hargreaves and Lawrence L. Spriet

Health Benefits of Exercise Gregory N. Ruegsegger and Frank W. Booth

Molecular Regulation of Exercise-Induced Muscle

Fiber Hypertrophy

Marcas M. Bamman, Brandon M. Roberts and Gregory R. Adams

Physiological Redundancy and the Integrative

Responses to Exercise Michael J. Joyner and Jerome A. Dempsey

On the Run for Hippocampal Plasticity C'iana Cooper, Hyo Youl Moon and Henriette van Praag

Molecular Basis for Exercise-Induced Fatigue: The Importance of Strictly Controlled Cellular $\mathrm{Ca}$

2+ Handling

Arthur J. Cheng, Nicolas Place and Håkan

Westerblad
Effects of Exercise and Aging on Skeletal Muscle Giovanna Distefano and Bret $H$. Goodpaster

Muscle-Adipose Tissue Cross Talk

Kristin I. Stanford and Laurie J. Goodyear

Performance Fatigability: Mechanisms and Task Specificity

Sandra K. Hunter

Adaptations to Endurance and Strength Training David C. Hughes, Stian Ellefsen and Keith Baar

The Bioenergetics of Exercise

$P$. Darrell Neufer

Effects of Exercise on Vascular Function,

Structure, and Health in Humans

Daniel J. Green and Kurt J. Smith

Control of Muscle Metabolism by the Mediator

Complex

Leonela Amoasii, Eric N. Olson and Rhonda

Bassel-Duby

Theoretical and Biological Evaluation of the Link between Low Exercise Capacity and Disease Risk Lauren Gerard Koch and Steven L. Britton

For additional articles in this collection, see http://perspectivesinmedicine.cshlp.org/cgi/collection/ 